\title{
Course diversity within South Australian secondary schools as a factor of successful transition and retention within Australian universities
}

\author{
Scott Wright \\ National Centre for Student Equity in Higher Education \\ University of South Australia
}

\begin{abstract}
There has long been a disparity in the provision of curriculum within Australian secondary schools. This study aims to evaluate whether diversity within schools alters students' university experiences. While much of the existing literature focuses on each aspect individually, this paper attempts to clarify a link between these factors by focussing on the transition process. A theoretical analysis of key concepts surrounding a web of inter-related issues, including student satisfaction, interest and motivation frames the quantitative data collection. The methodology employed consists of analysing a balanced sample of South Australian secondary schools, from an array of different locations, SES groupings and sizes, and an acknowledgement of previous studies into the first year experience within Australian Universities. The findings suggest that there is a disparity between learning areas in school curricula and an inherent link has been established with issues such as student attrition and dissatisfaction in universities.
\end{abstract}

Please cite this article as:

Wright, S. (2010). Course diversity within South Australian secondary schools as a factor of successful transition and retention within Australian universities. The International Journal of the First Year in Higher Education, 1(1), 21-30.

This article has been peer reviewed and accepted for publication in Int $J$ FYHE. Please see the Editorial Policies under the 'About' section of the Journal for further information.

(C) Copyright of articles is retained by author/s. As an open access journal, articles are free to use, with proper attribution, in educational and other non-commercial settings. ISSN: 1838-2959 


\section{Introduction}

There has long been a disparity in the provision of curriculum within Australian secondary schools (Teese, 1998). While many have a diverse and rounded array of courses, others have a limited few. This research paper aims to identify whether or not diversity in secondary schooling curriculum is complementary to student success within Australian universities.

There are two views from which the "value of diversity" debate can be observed - one from the perspective of schools, the other from university institutions. Both perspectives involve a particular position on three interrelated issues: student retention, engagement and satisfaction.

\section{Literature review}

Retention within schools is vital to the future successes of students in both higher education and their professional career opportunities (Smyth et al., 2000). The reasons for positive and negative school retention rates manifest differently depending on factors including location, socio-economic status and, most important to this study, curriculum provision and educational structure. In the United Kingdom (UK), Stables (1997) believes that retention, engagement and satisfaction is greater amongst upper secondary students who are free to exercise a large degree of "choice," compared to those who are exposed to limited curriculum opportunities. ${ }^{1}$

In order to understand why "choice" plays such a vital role, we must look at the subject from a psychological perspective. In Harris' (2008) phenomenographic analysis, respondents, consisting of secondary educators, identified "student interest" as the primary motivational force acting upon student participation and engagement in academic tasks. When students are motivated and focussed on a particular task, negative attitudes and behavioural problems become less apparent, inevitably improving their learning experience. As observed by Teese (2000) and Te Riele and Crump (2003), the most profound consequence of students not being interested in study is that they may choose not to complete education to a year twelve certificate level, restricting their post-school employment and higher education opportunities. In a survey of year twelve "drop-outs" by Lamb, Walstab, Teese, Vickers and Rumberger (2004), around a third of respondents identified "schooling-related reasons" as their motive for leaving, while a third of these specified "lack of interest" itself. ${ }^{2}$

In order to increase student retention and motivation, secondary schools need to cater to individual interests. Students' interests cover a broad range of disciplines and, while they may desire to choose subjects in which they have an interest, it is not always possible for them to do so. Although this can be blamed on a number of factors, a notable amount of dissatisfaction, through lack of interest and motivation in school-work, can be attributed to restricted curriculum offerings. In support of this, Elsworth, Harvey-Beavis, Ainley and

\footnotetext{
${ }^{1}$ Stables (1997) avers the opposite for students in lower-middle years, claiming that students are either illprepared to make selections, unaware of their true interests or future academic/professional aspirations, or can often make decisions based on simplicity of content.

2 "Schooling-related reasons" also include "dislike of school or teachers" and "poor academic performance." It should also be noted that Lamb et al. (2009) attribute "work-related reasons" as the principle cause of negative retention, to which "school-related reasons" is only secondary.
} 
Fabris (1999) provide the example that, while only a small number of students may engage in diverse courses of study, nearly a third more, given the opportunity, would take that path.

It should be acknowledged that if students cannot participate in "choice"-which they often consider to be their "right" - there may be a considerably greater, yet sub-conscious effect. Kress (2000) helps to clarify the relationship between choice and motivation in the $21 \mathrm{st}$ century academic climate. His historical comparison focuses upon observed, rather than documented analyses of society. He notes that, during the 19th century, the purpose of education was to adhere to academic heritage or promote future success. As products of their lineage and powerful social norms, students did not see "choice" as relevant to their academic lives - they were instead governed by external motivational factors rather than their own individualism. Today, as students become more aware of expanding opportunities available to them as a result of cultural and technological change, they are more likely to desire and act upon "choice." Assuming the same opportunities were made obvious to those in previous years, students would still have been governed by the social norms and expectations bestowed upon them by others. Since then, as highlighted by Kress, the greater liberalisation of society has led to students having more control over their own decisions and future aspirations - aspirations that may inform their curriculum and career choices. If unable to exercise "choice," students may be less inclined to complete secondary school or progress to further education.

While high school completion directly relates to students' ability to transition into tertiary study, there are also other underlying factors. Krause, Hartley, James and McInnis (2005) found that an overwhelming number of students consider "studying in their field of interest" to be an important factor in their decision to enrol. Yet, after a year, almost half discover that their chosen degree does not meet their initial expectations or maintain their interest.

Unsurprisingly, a similar number of students express a desire to defer from study or change degree, while more than a third believe their schools had not adequately prepared them for university study. The latter is reflected by the majority of respondents claiming that there was little cohesion between subjects they studied at school and university (Krause et al., 2005). This illustrates that, while students were confident that their chosen degrees would meet their expectations and maintain their interest, they later had a "change-of-heart" and considered their interests to no longer be reflective of those that had inspired their original choices.

From the data collected by Pargetter et al. (1998), it is possible to make the observation that students, in the pre-selection phase, consider that studying at university will give them the opportunity to expand their existing knowledge and undertake new experiences. This study suggests that students have confidence in their degree selections, yet, when asked about their motivations, they ranked "I will be able to study subjects in depth, and take interesting and stimulating courses" and "I want to develop as a person, broaden my horizons, and face new challenges" as most important. In order for students to find university experiences foreign and new, it is plausible to assume that they must have little knowledge of the content that their chosen degrees may contain. This level of uncertainty is realised when you observe the research of Pargetter et al. on "preparation," where students initially ranked their educational background as being valuable to their current studies, but, when queried in the latter part of their first year, were less enthusiastic.

Reflecting upon the work of Krause et al. (2005), it is impossible to ignore the notion that students begin to lose interest as the first year progresses. When compared to the 
investigations of Stables (1997), a clear notion of "poor preparation" is established, where students may not have been exposed to their interests at a school level. As a result, it is inherent that, when selecting degrees for study at university, students may be unsure of the actual content or subject matter they will be exposed to.

When taking into account the theoretical aspects presented by academics such as Stables (1997), and linking them with the practical analyses of Harris (2008) and Elsworth et al. (1999), the connection between interest, engagement, satisfaction and retention is clear. Students who do not experience the fortune of having a broad selection of subject choices are less likely to proceed to tertiary education or even complete secondary schooling. Of those who do complete school and wish to achieve academic advancement at university level, a notable number find that their degrees do not meet their expectations. It is evident from the work of Krause et al. (2005) that many students act upon these emotions and may cease enrolment, defer or change degree or institution. The desires that inspired them to enrol originally may have faded when the true nature of what they perceived to be their interests did not reflect the outcome they had hoped for. This begs the question: If students are able to gain experience with their perceived interests at secondary school level, will they make better informed decisions about their future courses of study and therefore continue enrolment until completion?

\section{Method}

In order to identify the representation of certain courses across South Australian secondary schools, curriculum handbooks were collected from schools of various "types," including metropolitan, regional, independent, and public institutions. Each school selection has been made with the acknowledgement of their socio-economic status, as defined by postcode indexes sourced from the Australian Bureau of Statistics (ABS) (2009). The curriculum analysed was selected from senior, South Australian Certificate of Education (SACE) year levels, with a specific focus on Stage $2 .^{3}$

The sample for this study consists of 16 metropolitan schools, separated into four subcategories of North, East, South and West, and four regional schools of various locations. In each four-school sub-category, two schools are independent and two are public. Within their respective regions, those in the highest and lowest SES postcodes were selected. This tiered selection process ensured there was adequate inclusion for a multitude of different populations, creating a clear and broad picture of curriculum provision.

After selections were made, the curriculum provided by the institutions, as outlined in publicly-available "curriculum handbooks," were compared to the subjects recognised under the SACE. Concurrently, the courses being offered were tallied into several categorical groupings, including The Arts, Co-curricular Studies, Design and Technology, English, Health and Physical Education, Languages other than English (LOTE), Mathematics, Science and Studies of Society and Environment (SOSE). From this, it was possible to make a comparison between the numbers of subjects offered per "learning area." This can be measured against the availability and frequency of participation in degrees undertaken at university level, also included in ABS data, and the opportunity students have to attain background knowledge within their field prior to enrolment. The aim of this approach was to

\footnotetext{
${ }^{3}$ The South Australian Certificate of Education (SACE) is currently undergoing significant reform, which may alter the provision of subject matter within South Australian Secondary Schools.
} 
identify possible "knowledge gaps" to reveal the reasons why a notable number of students do not experience cohesion between secondary and tertiary education and choose to cease or change their degree (Krause et al., 2005).

While new more localised research into students' perceptions and opinions would be a complementary method for this study, it was not possible to do so as a result of time and ethics constraints and the unavailability of student participants during the university "holiday period." ${ }^{4}$ Instead, student experiences evident in the First Year Experience Questionnaire (FYEQ) were employed to frame the collected data, providing a comparison between qualitative opinion and quantitative statistics. In an attempt to reveal changes in student opinion as they settled into their new educational environment, the FYEQ was prepared from student responses observed at both the onset and conclusion of their first year at university. While there are three revisions of the FYEQ, taken in 1994, 1999 and 2004, only the latest will be used. ${ }^{5}$

The aforementioned data collection enables the topic of curriculum diversity to be viewed from various angles - from an institutional and systematic perspective. By providing data relating to university populations and retention rates, a link can be made between each case.

\section{Analysis}

The discussion of this data is structured around two investigative arguments: the questions of (1) whether there is adequate and balanced representation, in relation to those that are deemed admissible by the SACE, between the subjects that are offered to students at school; and (2) how this compares to university degree intakes and student retention rates. The associated examination is scrutinized through the acknowledgement of variance and differences in subject provision between schools and universities, but from a "birds-eye view" where these are discussed as collective "systems" rather than as individual institutions.

The main data assets will be presented in the form of tables with accompanying graphs. Table 1 focuses on general curriculum provision within secondary schools, also including a breakdown of geographical groupings. Table 2 compares the number of SACE-recognised subjects per learning area and the average number of offerings within schools-which should reveal the diversity of curriculum provision. The remaining table and proceeding graph, as precursors to a discussion of data collated by Krause et al. (2005), provide an overview of the popularity of university degrees by learning area.

\footnotetext{
${ }^{4}$ This study was conducted over an eight week period from early January to late February, 2010. During this period, the majority of South Australian university students were between semesters and not available for interviews or related activities. Additionally, time constraints would not have made it possible to make a submission to a Human Research Ethics Committee to endorse equitable human research.

${ }^{5}$ It should be acknowledged that the data analysed from the FYEQ has not been sourced from original data sets, but from its accompanying report (Krause et al., 2005).
} 
Course diversity within South Australian secondary schools as a factor of successful transition and retention within Australian universities.

Representation in schools

Table 1 Subjects offered by learning area, South Australian Secondary Schools (sample) 2010

(Total sample consists of 20 schools, 4 per category)

\begin{tabular}{rcccccc}
\hline Learning Area & North & East & South & West & Regional & Total \\
\hline Arts & 23 & 20 & 24 & 23 & 19 & 109 \\
Co-curricular & 5 & 5 & 4 & 7 & 4 & 25 \\
Design and Technology & 16 & 16 & 17 & 15 & 16 & 80 \\
English & 8 & 13 & 12 & 12 & 6 & 51 \\
Health and Physical Education & 17 & 11 & 16 & 13 & 10 & 67 \\
Languages other than English (LOTE) & 8 & 13 & 15 & 5 & 5 & 46 \\
Mathematics & 12 & 14 & 14 & 11 & 11 & 62 \\
Science & 17 & 18 & 19 & 13 & 17 & 84 \\
Studies of Society \& Environment (SOSE) & 24 & 26 & 30 & 23 & 15 & 118 \\
\hline Total & 130 & 136 & 151 & 122 & 103 & 642 \\
\hline
\end{tabular}

Table 1 provides a picture of subject provision through conditions of location and subject learning area. Between locations, provision is relatively uniform; however, certain learning areas, such as English, LOTE and SOCE appear to be under-represented in regional schools. It is possible to infer that LOTE may not share the same educational spread as others due to issues surrounding teacher shortages and the necessity for multi-disciplinary teaching; however, the low proportion of English and SOSE courses is more surprising. Regional schools are not alone, with the Western and Northern metropolitan regions also exhibiting signs of difference. The Northern schools provide fewer English subject opportunities, with just under two thirds of those present in other metropolitan schools, while Science and LOTE are a third and two thirds less prominent, respectively, in the West, with Mathematics also being slightly under-represented. As expected, with a total marginally over a hundred, it is clear that regional schools have fewer subject choices than those in the metropolitan, which average almost a third higher. However, the data also reveals discrepancies within the metropolitan itself - most notably in the West, which has almost thirty less opportunities than the region with the broadest curriculum: the South.

The figures within Table 1 strongly suggest that there are obvious differences in course provision at secondary school level within South Australia. While this would no doubt result in students from particular schools, locations or SES groupings being unable to experience particular courses and act upon their interests, it is important to look at the system as a whole, investigating if particular learning areas may be under-represented in comparison to others. 


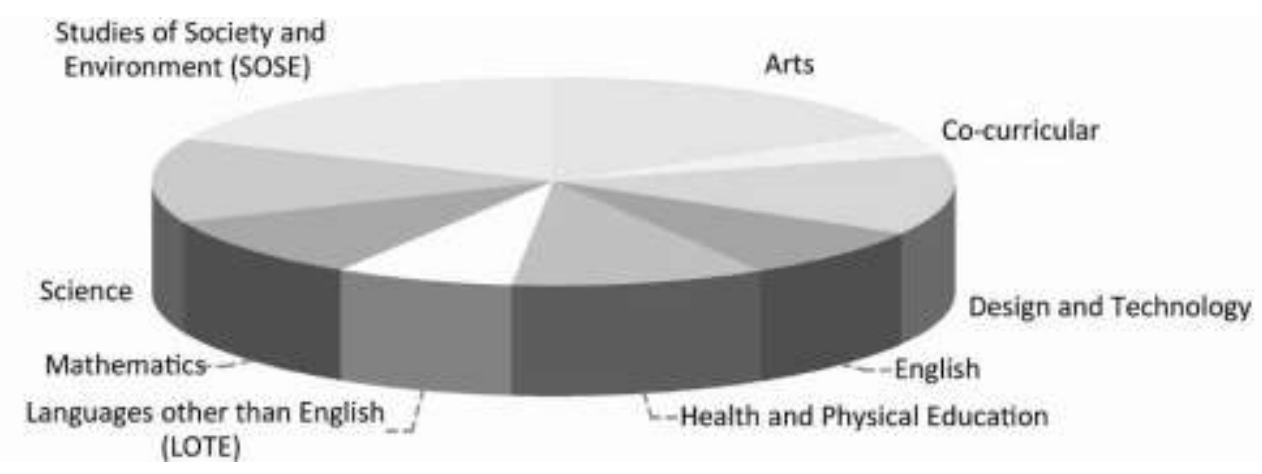

Figure 1 Subjects offered by learning area, South Australian Secondary Schools (sample) 2010

In general, as illustrated in Figure 1, the numbers of subjects for each learning area differ considerably, with The Arts, Design and Technology, Science and SOSE being more dominant than others such as LOTE, English, and Co-curricular studies. However, this is not representative of "actual" diversity because certain categories have greater "variety" than others. For example, only four Mathematics subjects are recognised by the SACE, compared to the eighteen subjects that are grouped under the banner of SOSE.

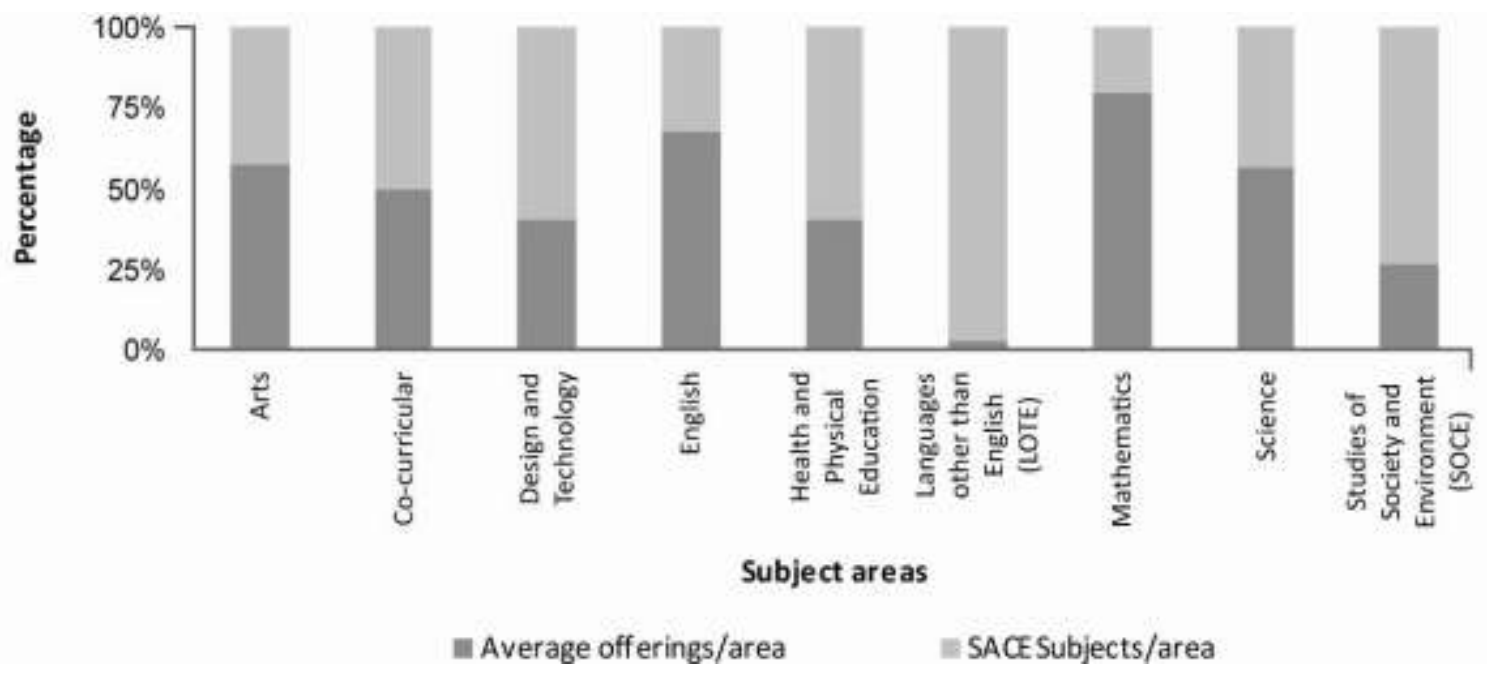

Figure 2 Number of subject offerings vs number of SACE-recognised subjects

To accurately gauge true representation, Table 2 and Figure 2 present the average number of subjects offered per learning area in schools, compared to the number of options recognised by the SACE. After observing the differences between the two, we can see that schools capitalise on providing subjects in groups associated with being "core" to academic success, such as The Arts, English, Mathematics and Science, which include over half of all SACE subject choices in their respective pools. In contrast, only a third of Health and Physical Education and SOSE subjects are provided. The latter is concerning when compared with the distribution of students per learning area within Australian universities. 
Course diversity within South Australian secondary schools as a factor of successful transition and retention within Australian universities.

Representation in universities

Table 3 Students studying a bachelor degree by field of study 2009 (National)

\begin{tabular}{rcc}
\hline *relative standard error of $25 \%$ to $50 \%, * *$ relative standard error greater than $50 \%$ \\
\hline Field of Study & $\mathbf{0 0 0}$ & Percentage (\%) \\
Natural and physical sciences & 52.6 & 7.2 \\
Information technology & 17.5 & 2.4 \\
Engineering and related technologies & 64.1 & 8.8 \\
Architecture and building & 13.1 & 1.8 \\
Agriculture, environmental and related studies & $5.6^{*}$ & 0.8 \\
Health & 110.4 & 15.2 \\
Education & 57.1 & 7.9 \\
Management and commerce & 180.8 & 24.9 \\
Society and culture & 149.3 & 20.6 \\
Creative arts & 63.4 & 8.7 \\
Toodal hospitality and personal services & $1.9 * *$ & 0.3 \\
\hline Total & 726.4 & 100.0
\end{tabular}

Source: Australian Bureau of Statistics (2009)

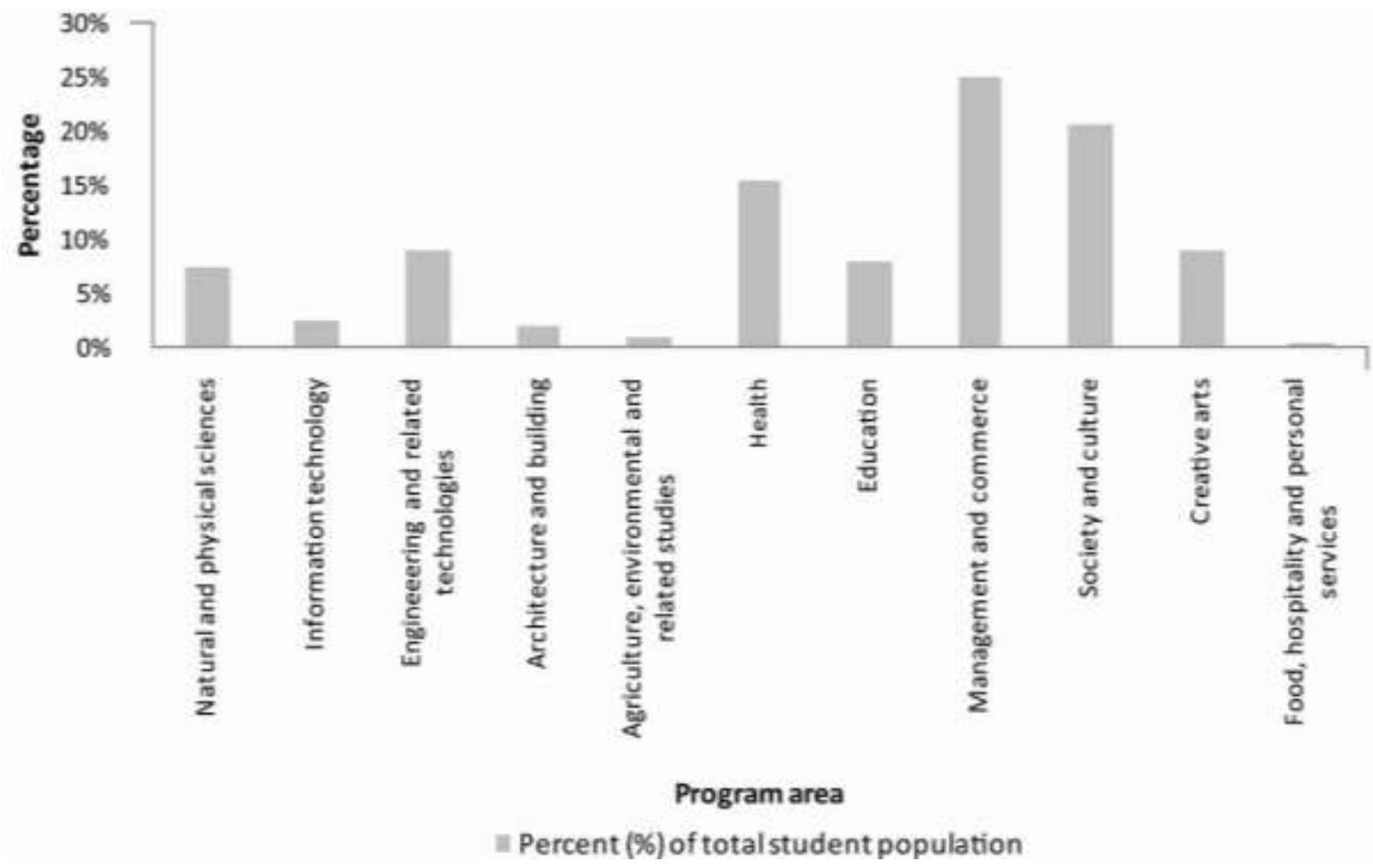


Figure 3 Students studying a bachelor degree by field of study 2009 (National)

Table 3 suggests that the university equivalents to SOSE, namely Education, Management and commerce and Society and culture, cater for more than half of all degrees undertaken by students at Australian institutions. With only a select group of SOSE subjects being offered in schools, students may leave institutions without the background knowledge or experience that may assist them in their future endeavours, should they choose to study in related university degrees. As discussed earlier, the greater majority of university students enrol in degrees within which they believe they have an intrinsic interest, yet almost a fifth express a desire to change degree after their first year. This is a clear indication that degrees undertaken by students often do not meet their expectations (Krause et al., 2005). It is safe to assume that if students were able to establish their true interests at school level, this level of uncertainty, and related dissatisfaction, could be minimised.

\section{Recommendations}

While it is impossible to foresee the effects that the "New SACE" or any future "National Curriculum" may have on curriculum within South Australian secondary schools, this paper has highlighted that, under the existing system, there are latent discrepancies in provision between learning areas. As mentioned, this results in schools having a curriculum that is inconsistent with degree offerings at Australian universities. The implications of students either (1) not having the opportunity to gain prior knowledge in their chosen fields and finding tertiary education different to what they expected or (2) not being able to realise their true interests and later becoming disenchanted with university, is an issue that can change the future career and education opportunities for students indefinitely.

To address this issue, curriculum designers should exercise caution, ensuring that an adequate balance between diversity and future opportunity is maintained. Where certain schools may be failing to provide diversity within particular disciplines, whether related to teaching, geographical, funding or other difficulties, measures could be taken to educate students via off-campus or correspondence education. Additionally, schools could make efforts to gauge student interest and assess what areas are relevant to their particular student populations, ensuring that both vocational and university learning pathways are established in tune with their needs. More importantly, further academic research needs to be conducted into the area to fully assess the situation and build a greater repository of knowledge capable of advising curriculum designers.

\section{References}

Australian Bureau of Statistics. (2009). 6227.0 - Education and work, Australia, May 2009. Retrieved January 4, 2010, from http://www.abs.gov.au/AUSSTATS/abs@.nsf/DetailsPage/6227.0May\%202009

Elsworth, G. R., Harvey-Beavis, A., Ainley, J., Fabris, S. (1999). Generic interests and school subject choice. Educational Research and Evaluation, 5(3), 290-318. Retrieved January 15, 2010, from http://www.informaworld.com/index/4JY0L5QRY6P2UCQ1.pdf

Harris, L. R. (2008). A phenomenographic investigation of teacher conceptions of student engagement in learning. Australian Educational Researcher, 35(1), 57-79. Retrieved January 15, 2010, from http://www.eric.ed.gov/ERICWebPortal/recordDetail?accno=EJ793463 
Krause, K., Hartley, R., James, R. \& McInnis, R. (2005). The first-year experience in Australian universities: Findings from a decade of national studies. Melbourne, Australia: Centre for the Study of Higher Education. Retrieved January 15, 2010, from http://www.dest.gov.au/NR/rdonlyres/1B0F1A03-E7BC-4BE4-B45C735F95BC67CB/5885/FYEFinalReportforWebsiteMay06.pdf

Kress, G. (2000). A curriculum for the future. Cambridge Journal of Education, 30(1), 133145. Retrieved January 7, 2010, from http://www.informaworld.com/index/L905HYAT2YT2FMBU.pdf

Lamb, S., Walstab, A., Teese, R., Vickers, M. \& Rumberger, R. (2004). Staying on at school: Improving student retention in Australia. Melbourne, Australia: Centre for Postcompulsory Education and Lifelong Learning. Retrieved February 4, 2010, from http://www.curriculum.edu.au/verve/_resources/studentretention_main_file.pdf

Pargetter, R., Mcinnis, C., James, R., Evans, M., Peel, M. \& Dobson, I. (1998). Transition from secondary to tertiary: A performance study. Retrieved February 4, 2010, from http://www.dest.gov.au/archive/highered/eippubs/eip98-20/contents.htm

Smyth, J., Hattam, R., Cannon, J., Edwards, J., Wilson, N. \& Worst, S. (2000). Listen to me I'm leaving -Early school leaving in South Australian secondary schools. Adelaide, Australia: Flinders Institute for the Study of Teaching.

Stables, A. (1997). Perspectives on subject choice: The case for a humane liberalism in curriculum planning. Journal of Curriculum Studies, 29(2), 197-208. Retrieved January 7, 2010, from http://www.informaworld.com/index/rxyldhqxxrhqdh88.pdf

Teese, R. (1998). Curriculum hierarchy, private schooling, and the segmentation of Australian secondary education, 1947-1985. British Journal of Sociology of Education, 19(3), 401-417. Retrieved January 7, 2010, from http://www.jstor.org/stable/1393243

Teese, R. (2000). Post-compulsory education and training: Some recent research findings and their policy implications. The Australian Education Researcher, 27(3), 49-58. Retrieved January 7, 2010, from http://www.edfac.unimelb.edu.au/cpell/CPET/documents/postcompulsary.pdf

Te Riele, K. \& Crump, S. (2003). Ongoing inequality in a "knowledge economy": Perceptions and actions. International Studies in Sociology of Education, 13(1), 5575. 